\title{
RANCANG BANGUN SISTEM APLIKASI RESERVASI AULA MASJID AL-HUDA MUHAMMADIYAH TEBET TIMUR
}

\author{
Karimah $^{1}$, Arif Susanto ${ }^{2}$, Ulfa Pauziah ${ }^{3}$ \\ Program Studi Informatika, Fakultas Teknik dan Ilmu Komputer, Universitas Indraprasta PGRI \\ Jalan Raya Tengah No. 80, Kelurahan Gedong, Pasar Rebo, Jakarta Timur \\ Karimahrima97@gmail.com ${ }^{1}$, arif_susanto3@yahoo.com², pelangi_ulfa@yahoo.com ${ }^{3}$
}

\begin{abstract}
Abstrak
Aula Masjid Al-Huda Muhammadiyah Tebet Timur yang bergerak dalam bidang pelayanan penyewaan tempat, dalam pencatatan jadwal sering terjadi human error yang karena masih dilakukan secara manual, dan sulitnya pengecekan jadwal booking karena media pencatatn yang digunakan masih memakai media kertas. Sehingga, perlu adanya suatu sistem aplikasi reservasi, aplikasi ini dibuat guna membantu kinerja pegawai dalam hal penyewaan sehingga tidak banyak buku yang dikeluarkannya untuk pencatatan sehingga dapat membantu dalam membuat laporan yang tepat dan akurat serta untuk membantu mengendalikan proses penyewaan fasilitas Aula Masjid Al-Huda Muhammadiyah Tebet Timur. Penyewaan aula seperti laporan data penyewa, data booking, data pelunasan, data pembatalan per periode, serta laporan bukti booking, bukti pelunasan, dan bukti pembatalan, yang dapat mempermudah admin aula dalam mengolah data-data tersebut karena data-data tersebut tersimpan di database dengan rapih, teratur, serta aman. Metode penelitian yang ini yaitu menggunakan metode Grounded Research yaitu suatu metode penelitian yang berdasarkan pada fakta dan menggunakan analisis perbandingan dengan tujuan mengadakan generalisasi empiris, menetapkan konsep, membuktikan teori, mengembangkan teori, pengumpulan dan analisis data dalam waktu yang bersamaan. Tujuan dengan adanya aplikasi ini nantinya akan akan memudahkan dalam pengolahan data pembuatan laporan.
\end{abstract}

Kata Kunci : Sistem Informasi, Pengolahan Data, Reservasi Aula

\begin{abstract}
The Hall of Masjid Al-Huda Muhammadiyah Tebet Timur engaged in rental services, in recording schedules often occurred human error because it is still done manually, and difficult to check the booking schedule because the recording media used still use paper media. Therefore, there must be a reservation application system, this application is useful to help the performance of employees in terms of rental so that there are not many books issued for recording so that it can be helpful in making precise and accurate reports and to help control the rental process facilities of the Hall of Masjid Al-Huda Muhammadiyah Tebet Timur. Hall rental such as tenant data report, booking data, repayment data, cancellation data per period, as well as booking proof reports, proof of payment, and proof of cancellation, which can facilitate the hall admin in processing such data because the data is stored in a neat, orderly database, as well as safe.. The research method used is using the Grounded research Method, a research method based on facts and using comparative analysis with the aim of conducting empirical generalizations, establishing concepts, proving theories, developing theories, collecting and analyzing data at the same time. The purpose of this application will later be to facilitate the processing of the report generation data.
\end{abstract}

Keywords: Information Systems, Data Processing, Hall Reservations

\section{PENDAHULUAN}

Komputer sebagai perangkat teknologi canggih akhirnya terpilih sebagai salah satu alternatif yang paling mungkin dalam membantu menyelesaikan pekerjaan dan menangani arus informasi dalam jumlah yang besar. Bukti ini dapat dilihat dengan semakin banyaknya penggunaan komputer yang digunakan untuk menyimpan dan mengolah data sehingga menjadi suatu informasi yang dimanfaatkan oleh berbagai kalangan yang membutuhkannya. Salah satunta dalam proses reservasi sebuah aula karena dapat mempemudah kinerja pegawai dalam memaksimalkan proses reservasi aula itu sendiri. Melihat kebutuhan dan situasi Aula Masjid Al-Huda Muhammadiyah Tebet Timur yang bergerak dalam bidang pelayanan penyewaan tempat yang masih dilakukan secara manual yang rentan terjadi kesalahan dalam pencatatan. Sehingga, perlu adanya suatu Sistem Aplikasi Reservasi, aplikasi ini dibuat guna membantu kinerja pegawai dalam hal penyewaan sehingga tidak banyak buku yang dikeluarkannya untuk pencatatan sehingga dapat membantu dalam membuat laporan yang tepat 
dan akurat serta untuk membantu mengendalikan proses penyewaan fasilitas Aula Masjid Huda Muhammadiyah Tebet Timur.

Bedasarkan latar belakang di atas, maka peneliti memberika solusi kendala-kendala pada proses pengolahan data reservasi aula, merancang sistem aplikasi reservasi Aula Al-Huda Muhammadiyah Tebet Timur, dan memberikan solusi bagaimana mengolah serta menyimpan data-data penyewa aula agar tetap aman. Tujuan penelitian ini berdasarkan permasalahan diatas, maka peneliti mendapatkan gambaran tentang sistem yang sedang berjalan dan mengetahui masalah yang dihadapi sebagai acuan pembuat sistem yang lebih efektif dan efisien, mengurangi masalah human error dalam mengolah data penyewa aula, jadwal penyewa aula, serta pembuatan laporan sehingga dapat meningkatkan akurasi data, memberikan suatu solusi dengan merancang sebuah sistem aplikasi reservasi Aula Al-Huda Muhammadiyah Tebet Timur agar lebih cepat, tepat dan akurat, dan untuk membuat sistem aplikasi reservasi aula yang terkomputerisasi sehingga memudahkan karyawan dalam mengolah data aula. Penelitian ini diharapkan memberi manfaat bagi Masjid Al-Huda Muhammadiyah Tebet dalam mendapatkan sistem baru yang lebih efektif dan dapat memudahkan mengolah data-data yang dibutuhkan dengan cepat dan akurat dan memudahkan karyawan Aula Masjid Al-Huda Muhammadiyah Tebet dalam mencatat serta mencari data penyewa.

\section{PENELITIAN RELEVAN}

Dalam rangka mendapatkan hasil penelitian yang baik, selain melakukan penelitian secara langsung peneliti juga melakukan kajian pustaka. Dari hasil penelitian yang telah dilakukan. Beberapa hasil acuan yang menjadi acuan adalah:

Penelitian (Aisyah et al., 2019) dari yang berjudul "Sistem Penyewaan Gedung Serbaguna Di Masjid Agung AL-Barkah Bekasi”. Masjid Agung Al-Barkah merupakan sebagai Masjid Pusat Syiar dan Dakwah Islam, dengan visi An-Nashiruth Thagyir (pusat perubahan) bermanfaat guna kepentingan umat islam khususnya di Kota Bekasi. Disamping itu Gedung Serbaguna Al-Barkah, merupakan bangunan Masjid lama yang sudah direnovasi sedemikian rupa yang letaknya sebelah barat Masjid dan untuk memenuhi keinginan dan harapan masyarakat maka Masjid Agung Al-Barkah menyediakan jasa penyewaan gedung untuk berbagai acara. Untuk membuat sistem penyewaan gedung di Masjid Agung Al-Barkah, Menggunakan sistem Unified Modelling Language (UML), Diagram UML. maka Penyajian sistem penyewaan gedung serbaguna dengan cara pemesanan, pembayaran yang masih dilakukan secara manual bisa terdapat resiko kesalahan dalam pencatatan, dalam mengelola penyewaan gedung serbaguna.

Penelitian dari (Pahlevi, 2016) yang berjudul "Perancangan Sistem Informasi Reservasi Online Pad Hotel XXX". Reservasi online sangat dibutuhkan oleh sebuah perusahaan perhotelan agar bisa tetap bersaing secara modern demi meningkatkan pelayanan. Untuk mempercepat dan memudahkan pelayanan terhadap pengunjung diperlukannya sistem berbasis web agar dapat melakukan reservasi atau pemesanan kamar denganjarakjauh tanpa harus datang terlebih dahulu ke lokasi atau menggunakan telepon.

Penelitian dari (Setiawan et al., 2019) yang berjudul "Perancangan Sistem Reservasi Gedung Dan Aula Berbasis Web Di Wilayah Banjarmasin". Gedung dipilih berdasarkan kapasitas ruang, fasilitas umum, dan fasilitas khusus, lokasi gedung, luasnya halaman dan lain-lain, Kendalanya terkadang sebelum memilih gedung, penyewa harus ekstra fisik untuk survey ke beberapa tempat atau gedung, karena terkadang tidak ada yang tahu koordinasi waktu penggunaan gedung tersebut antara gedung yang satu dengan gedung lainnya. Dengan adanya sistem ini diharapkan menjadi informatif dan memudahkan bagi penyewa dalam mengakses seluruh informasi mengenai gedung-gedung yang mereka inginkan mulai dari mengelola seluruh informasi yang diperlukan bagi penyewa, mulai dari jarak terdekat, budget, kapasitas, fasilitas penunjang dan waktu kosong yang bisa di booking penyewa Penelitian dari (Prasetia, 2018) yang berjudul "Sistem Informasi Reservasi Gedung Serbaguna Dikota Palembang Berbasis Android". Pada penelitian ini peneliti menggunakan metode Prototype sebagai metode pengembangan dan permodelan menggunakan UML (Unified Model Language) sedangkan pembuatan aplikasinya sendiri menggunakan bahasa pemrograman Java pada bagian android dan bahasa pemograman PHP pada bagian website dengan MySQL untuk pengolahan databasenya. Sistem informasi reservasi gedung serbaguna di Kota Palembang berbasis android dapat mengumpulkan, mengidentifikasi, menyimpan, mengelola dan memberikan informasi beberapa gedung serbaguna yang ada di kota Palembang yang dijadikan sample dalam penelitian ini. 
Penelitian dari (Hutahaean \& Wardani, 2019) yang berjudul "Pengembangan Sistem Informasi Penyewaan Gedung Berbasis Web Dengan Metode Rational Unified (RUP) (Studi Kasus: Wisma Rata Medan)". Wisma Rata adalah salah satu penyedia penyewaan gedung yang bisa digunakan untuk acara pernikahan, adat dan acara sejenisnya di kota Medan, Sumatera Utara. Wisma Rata masih menggunakan buku besar dalam proses pencatatan data. Walaupun data yang telah tersimpan didalam buku besar dirasa sudah cukup untuk saat ini, tetapi pada saat proses pengelolaan data pemesanan dan pencarian jadwal ketersediaan gedung selalu mengalami kendala dalam pencarian data yang tidak efisien. . Dikarenakan permasalahan itu, diberikan solusi sebuah sistem informasi penyewaan gedung yang dapat membantu proses pemesanan penyewaan gedung, pengecekan ketersediaan gedung, penyimpanan data pemesanan, dan perekapan data pemesanan. Metode Rational Unified Process (RUP) digunakan dalam mengembangkan sistem dengan fase insepsi, elaborasi, konstruksi dan transisi. Sistem informasi yang telah dikembangkan mendapatkan hasil pengujian validasi dengan hasil $100 \%$ valid dan pengujian compatibility dengan hasil yaitu sistem dapat diakses pada browser yang berbeda. User Acceptance Testing kemudian diujikan pada lima responden dari masing-masing aktor menunjukkan sistem informasi penyewaan gedung Wisma Rata Medan dapat diterima dengan baik oleh pengguna.

\section{METODE PENELITIAN}

Metode penelitian yang digunakan untuk melakukan penelitian adalah metode grounded (grounded research). Menurut (Sugiyono, 2013) Metode Grounded Research yaitu suatu metode penelitian yang berdasarkan generasi empiris, menetapkan konsep, membuktikan teori, mengembangkan teori, mengumpulkan dan analisis data dalam waktu yang bersamaan. Setelah mengumpulkan data, peneliti melanjutkan proses penelitian sesuai dengan langkah-langkah pokok yang digunakan pada metode ini, yaitu menentukan masalah yang ingin diselidiki, mengumpulkan data atau informasi yang ada di lapangan, menganalisis dan menjelaskan masalah yang ditemukan serta membuat laporah hasil penelitian. Metode pengumpulan data yang digunakan Peneliti untuk mendapatkan data dan informasi yang mendukung penyempurnaan hasil dari penelitian ini antara lain:

1. Studi Kepustakaan

Pengumpulan data dan informasi dari kutipan buku-buku, peraturan perundang-undangan, artikelartikel, hasil laporan, serta bahan lainnya yang berkaitan dengan penelitian ini. Dari bahan-bahan tersebut diambil teori-teori yang dapat dijadikan landasan untuk menganalisa masalah yang ditemukan dalam penelitian yang digunakan untuk menyelesaikan masalah tersebut.

2. Studi Lapangan dilakukan dengan melihat langsung penerapan proses produksi dan pemensanan, dalam studi lapangan ini dipergunakan teknik pengumpulan data antara lain dengan cara:

a) Wawancara

Teknik pengumpulan data dengan cara bertanya kepada pelaksana atau pemilik yang terlibat langsung dalam kegiatan pemesanan atau reservasi dari Aula Masjid Al-Huda Muhammadiyah Tebet Timur.

b) Observasi

Peneliti melakukan survei atau observasi untuk mengamati secara langsung proses pemesanan dan pengolahan data yang dilakukan oleh Aula Masjid Al-Huda Muhammadiyah Tebet Timur

c) Sumber Data

Data dan informasi yang diperoleh untuk mendukung penelitian ini diambil dari berbagai sumber data sekunder yang merupakan data pendukung untuk melengkapi data primer yang diperoleh melalui Tanya jawab langsung atau dokumen yang tersedia.

\section{HASIL DAN PEMBAHASAN}

Alternatif penyelesaian masalah yang peneliti usulkan adalah berupaya membuat sistem aplikasi yang dapat mengatasi masalah-masalah yang terjadi dalam data-data customer dan layanan jasa yang tersedia. Sistem aplikasi yang akan peneliti buat, menggunakan Bahasa pemrograman java dengan mengunakan database MySQL sebagai tempat penyimpanan data-data perusahaan. Sistem ini diharapkan mampu memberikan kemudahan bagi siapa saja yang akan memakainya dan mempermudah dalam pengolahan data-data customer dan data tanggal yang tersedia. Dengan penyimpanan data media database nantinya akan mempermudah dalam pencarian data-data yang yang dibutuhkan dalam pembuatan laporan, pencarian data customer hingga data tanggal yang tersedia. Aplikasi yang nant- 
inya akan digunakan berbasis desktop dan penyimpanan data pada database, akan memudahkan dalam pengolahan data pembuatan laporan.

\section{Diagram Alir Data (DAD) Sistem yang Diusulkan (Diagram Konteks, Nol, Rinci) Diagram Konteks}

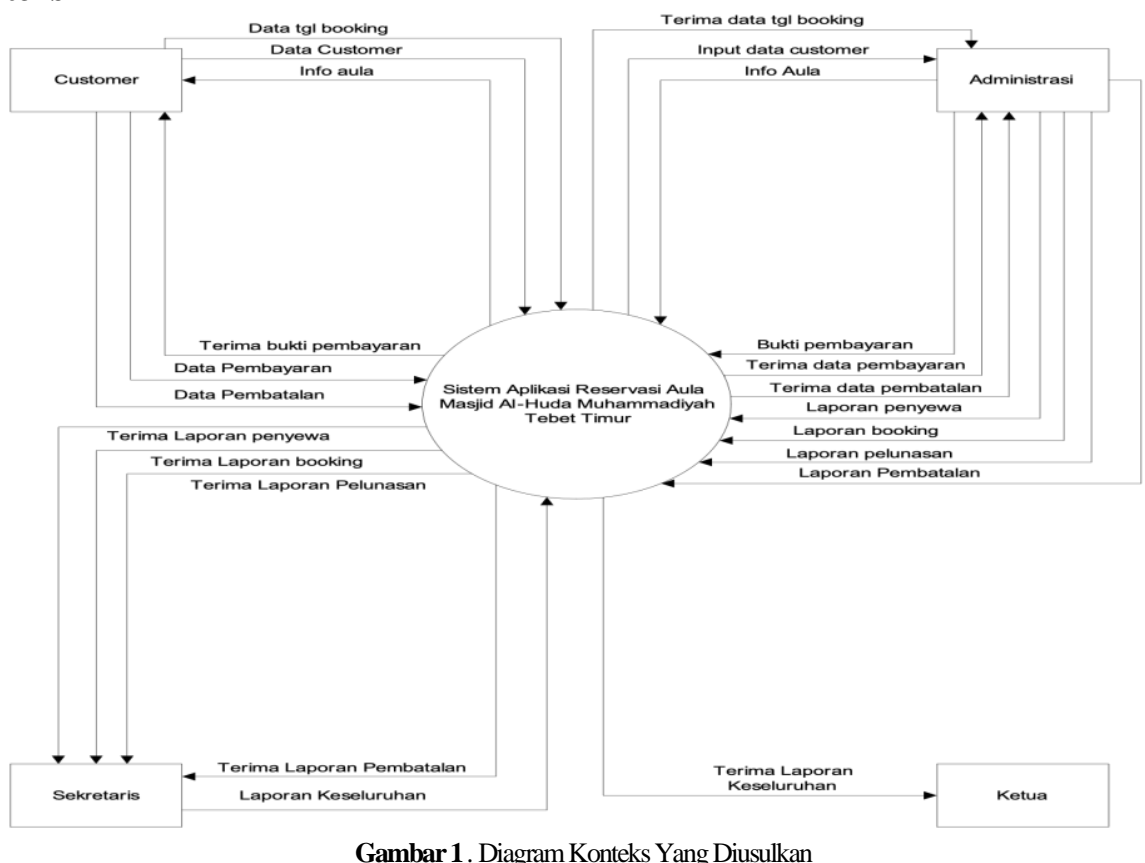

Pada diagram diatas memperlihatkan gambaran umum dari subsistem rancang bangun sistem absensi dan penilaian karyawan, karena seluruh subsistem hanya diwakili oleh satu simbol proses. Subsistem aplikasi reservasi aula masjid, berinteraksi dengan kesatuan luar atau kelompok pengguna yaitu customer, administrasi, sekretaris, dan ketua. Customer dapat membooking aula, mengetahui info aula, serta memberikan data pribadi kepada pihak administrasi sebagai syarat booking. Administrasi bisa mengakses semua data aula, customer, data boking aula, serta membuat semua laporan dari sistem reservasi aula. Seketaris menerima laporan penyewa, booking, pelunasan serta pembatalan. Ketua dapaet melihat seluruh laporan dari sistem aplikasi reservasi aula.

\section{Entity Relationship Diagram (ERD)}
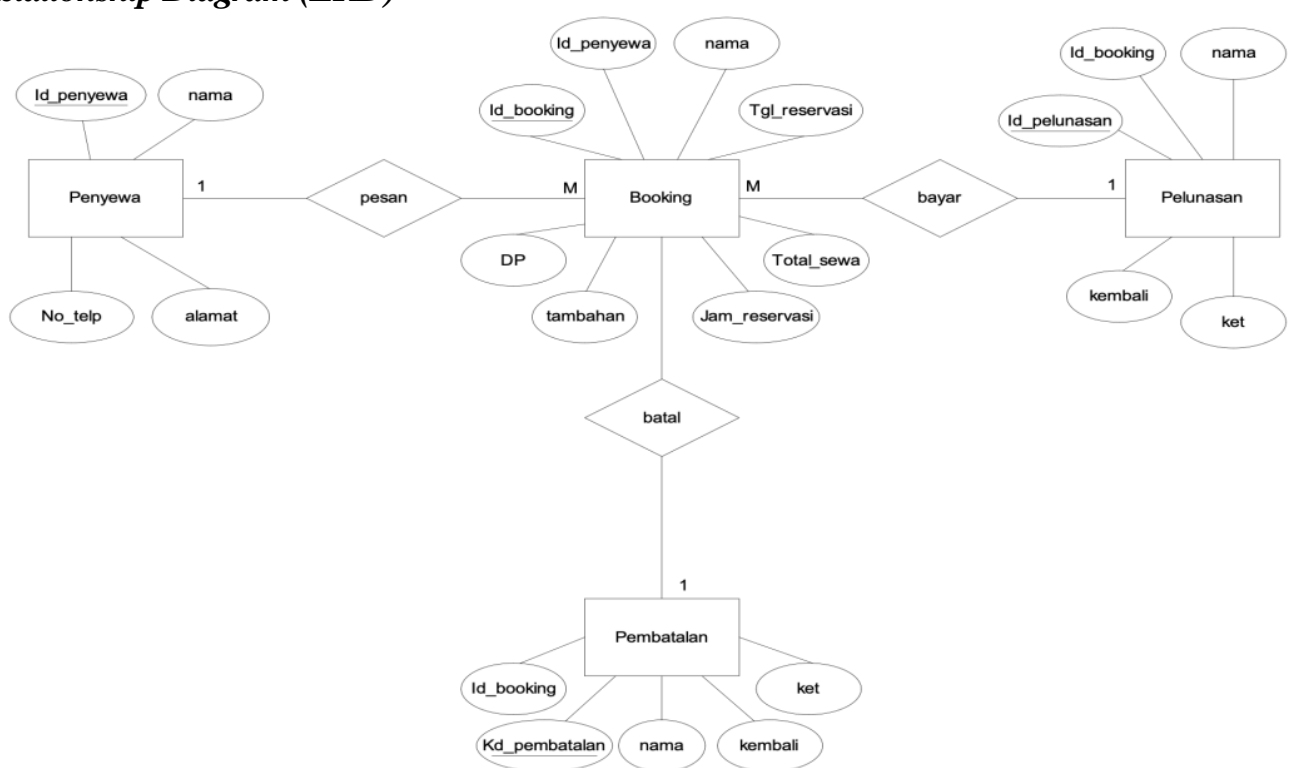

Gambar 2. ERD (Entity Relationship Diagram) 
Pada gambar diatas dapat dijelaskan bahwa customer dapat menyewa serta memesan aula sesuai tanggal yang ditentukan dan melakukan pelunasan sesuai harga yang ditentukan pihak aula Masjid Al-Huda Muhammadiyah Tebet Timur. Serta customer dapat membatalkan reservasi aula.

\section{Rancangan Tampilan Layar}

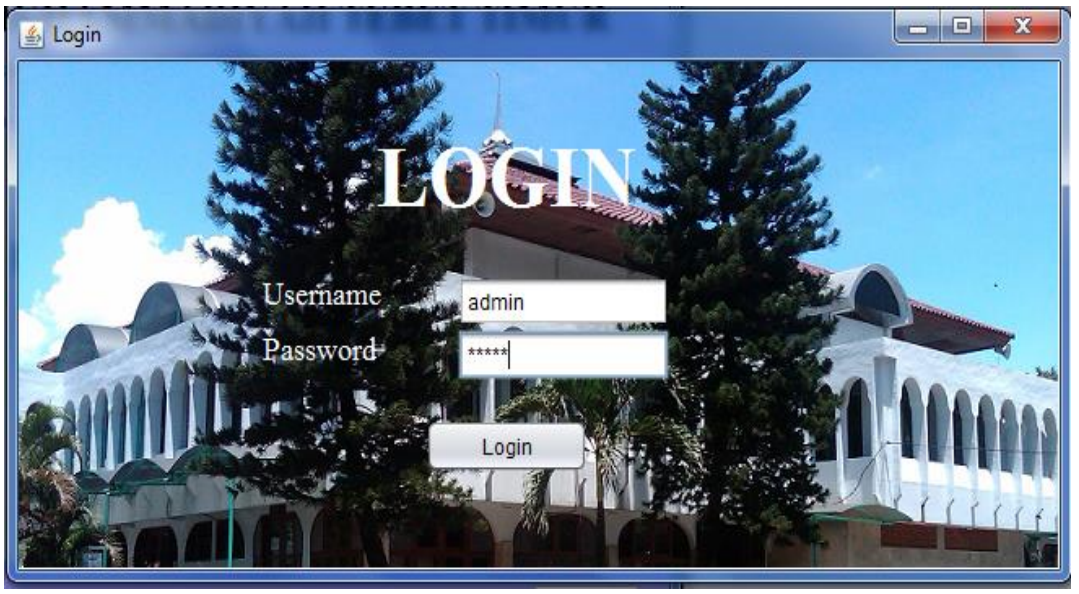

Gambar 3. Tampilan Menu Login

Tampilan ini terdapat pada awal program. Menu login digunakan sebagai kata kunci sebelum kita memasuki menu utama atau menu Reservasi. Agar tidak sembarangan orang dapat mengakses program ini. Sehingga dalam form menu kerahasiaanya dapat terjaga dengan baik. Pengguna atau user harus mempunyai akses berupa username dan password untuk dapat menggunakan aplikasi tersebut.

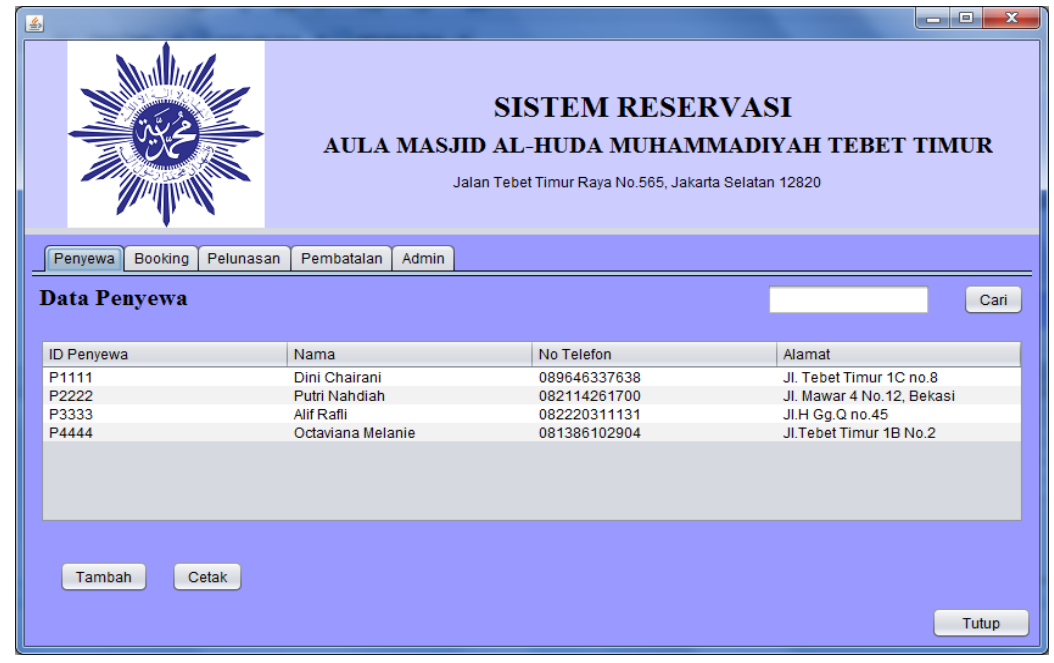

Gambar 4. Tampilan Menu Utama

Layar diatas menampilkan tampilan menu utama Sistem Aplikasi Reservasi Aula Masjid Al-Huda Muhammadiyah Tebet Timur, pada layar utama menampilkan pilihan tabel Data Penyewa, Data Booking, Data Pelunasan, Data Pembatalan serta Data Admin. Serta dilengkapi dengan tombol tambah untuk menambahkan atau menginput data baru dan tombol cetak untuk mencetak laporan. 


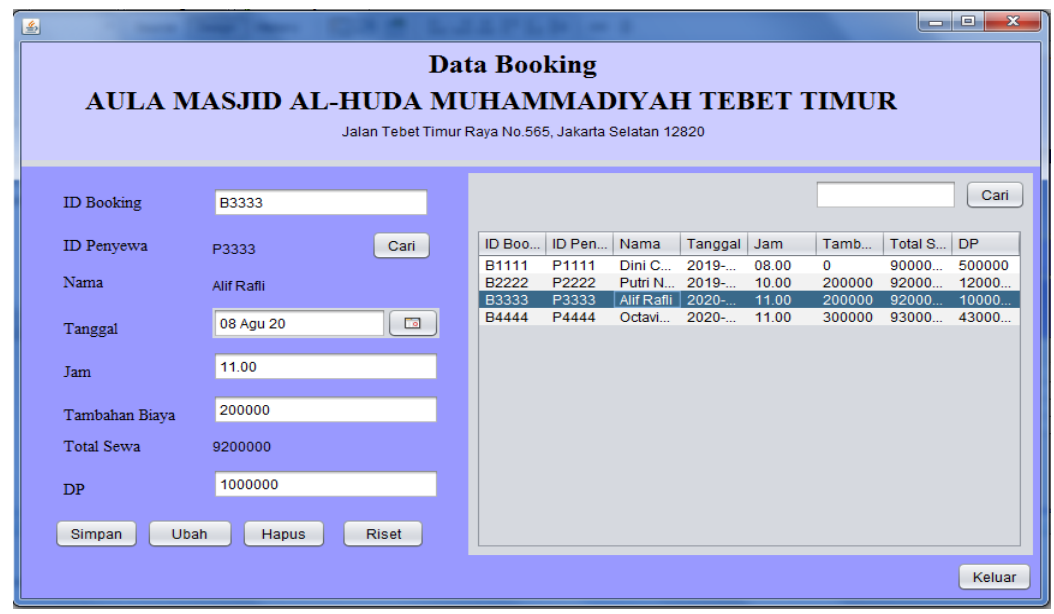

Gambar 5. Tampilan Form Booking

Dalam form penyewa ini berfungsi untuk mencatat tanggal serta waktu penyewaan aula yang akan di sewa serta mengambil data penyewa dari Pop-Up Data Penyewa yang dapat memudahkan dalam mencari data penyewa aula.

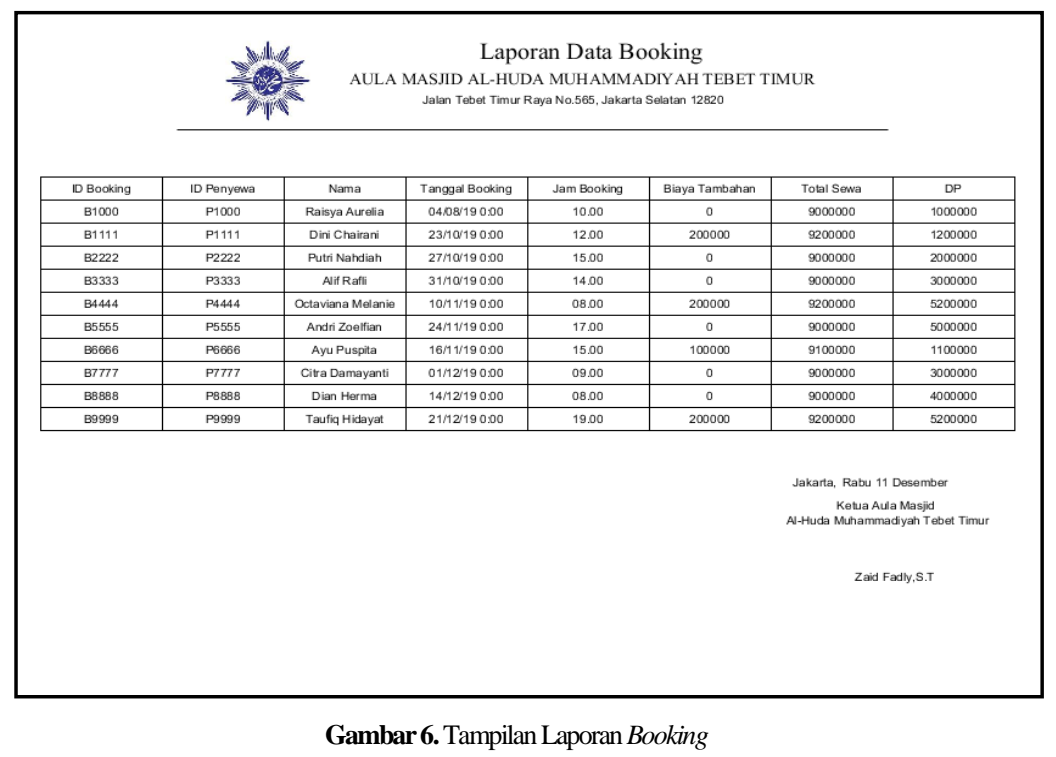

Laporan ini dapat kita lakukan setelah kita menekan tombol cetak pada halaman reservasi kolom booking. Laporan ini berisi Data tanggal, jam, serta biaya sewa aula masjid Al-Huda Muhammadiyah Tebet Timur.

\section{SIMPULAN}

Dari hasil pembahasan yang telah diuraikan pada bab-bab sebelumnya, maka dapat disimpulkan bahwa dengan adanya Sistem Aplikasi Reservasi Aula Masjid Al-Huda Muhammadiyah Tebet Timur ini dapat memudahkan admin aula dalam melakukan pengolahan data reservasi penyewaan aula yang ada di Aula Masjid AL-Huda Muhammadiyah Tebet Timur. Dengan menggunakan Sistem Aplikasi Reservasi Aula Masjid Al-Huda Muhammadiyah Tebet Timur ini dapat mengefisiensikan waktu serta mempermudah kinerja admin dalam melakukan pelayanan penyewaan aula dan pembuatan laporan penyewaan. Sistem Aplikasi Reservasi Aula Masjid Al-Huda Muhammadiyah Tebet Timur ini dapat meminimalisir adanya kesalahan pencatatan data penyewa serta pencarian tanggal booking yang sudah di booking. Dengan adanya Sistem Aplikasi Reservasi Aula Masjid Al-Huda Muhammadiyah Tebet Timur ini, data-data yang disimpan lebih terstruktur dan juga lebih aman. 


\section{DAFTAR PUSTAKA}

Aisyah, Nurul, Asep, A. Y. (2019). SISTEM PENYEWAAN GEDUNG SERBAGUNA DI MASJID AGUNG AL-BARKAH BEKASI. Jurnal Interkom, (Vol. 14 No. 2 - Juli).

Hutahaean, David Josua, Niken Hendrakusma Wardani, W. P. (2019). Pengembangan Sistem Informasi Penyewaan Gedung Berbasis Web dengan Metode Rational Unified Process (RUP) (Studi Kasus: Wisma Rata Medan). Jurnal Pengembangan Teknologi Informasi dan Ilmu Komputer, (Vol. 3, No. 6, Juni), 5789-5798.

Pahlevi, Pahlevi, M. F. (2016). Perancangan Sistem Informasi Reservasi Online Pada Hotel "XXX.” UG jurnal, (Vol. 10 No. 03), 31-37.

Prasetia, Andi Ahmad. (2018). Sistem Informasi Reservasi Gedung Serbaguna di Kota Palembang Berbasis Android. Jurnal Intelektualita: Keislaman, Sosial, dan Sains, (Volume 7, Nomor 1, Juni), 121-128.

Setiawan, Agus, Agus Alim Muim, B. R. (2019). PERANCANGAN SISTEM RESERVASI GEDUNG DAN AULA BERBASIS WEB DI WILAYAH BANJARMASIN. Jurnal Ilmiah ”Technologia”, (Vol 10, No.1, Januari-Maret), 1-4.

Sugiyono. (2013). Metode Penelitian Kuantitatif dan R \& D. Bandung: Alfabeta. 